Research Paper

\title{
CD44v6 Monoclonal Antibody-Conjugated Gold Nanostars for Targeted Photoacoustic Imaging and Plasmonic Photothermal Therapy of Gastric Cancer Stem-like Cells
}

\author{
Shujing Liang1,2, Chao Li², Chunlei Zhang2, Yunsheng Chen², Liang $\mathrm{Xu}^{1}$, Chenchen $\mathrm{Bao}^{2}$, Xiaoyong Wang ${ }^{3}$, \\ Gang liu ${ }^{3}$, Fengchun zhang ${ }^{1 凶, 4}$, Daxiang Cui ${ }^{2 \bowtie}$ \\ 1. Rui Jin Hospital Affiliated to Shanghai Jiao Tong University School of Medicine, Shanghai 200025, P. R. China \\ 2. Institute of Nano Biomedicine and Engineering, Key Laboratory for Thin Film and Microfabrication of Ministry of Education, Department of \\ Instrument Science and Engineering, Research Institute of Translational Medicine, Shanghai Jiao Tong University, Shanghai 200240, P. R. China \\ 3. Center for molecular imaging and Translational medicine of Xiamen University, Xiamen 361102, P. R. China \\ 4. Suzhou Kowloon Hospital Shanghai Jiaotong University School of Medicine.
}

\begin{abstract}
$\triangle$ Corresponding authors: Fengchun Zhang, Rui-Jin Hospital Affiliated to Shanghai Jiao Tong University School Of Medicine, 197Ruijin Rd II, Shanghai 200025 China; and Suzhou Kowloon Hospital Shanghai Jiaotong University School of Medicine. E-mail: fczhang2004@163.com. Or Daxiang Cui, Institute of Nano Biomedicine and Engineering, Research Institute of Translational Medicine, Shanghai Jiao Tong University, 800 Dongchuan Road, Shanghai 200240, P. R. China. Tel: +86-21-34206375. Fax: +86-21-34206886. E-mail: dxcui@sjtu.edu.cn

(c) 2015 Ivyspring International Publisher. Reproduction is permitted for personal, noncommercial use, provided that the article is in whole, unmodified, and properly cited. See http://ivyspring.com/terms for terms and conditions.
\end{abstract}

Received: 2015.01.19; Accepted: 2015.05.07; Published: 2015.06.01

\begin{abstract}
Developing safe and effective nanoprobes for targeted imaging and selective therapy of gastric cancer stem cells (GCSCs) has become one of the most promising anticancer strategies. Herein, gold nanostars-based PEGylated multifunctional nanoprobes were prepared with conjugated CD44v6 monoclonal antibodies (CD44v6-GNS) as the targeting ligands. It was observed that the prepared nanoprobes had high affinity towards GCSC spheroid colonies and destroyed them completely with a low power density upon near-infrared (NIR) laser treatment $(790 \mathrm{~nm}, 1.5$ $\mathrm{W} / \mathrm{cm}^{2}, 5 \mathrm{~min}$ ) in vitro experiment. Orthotopic and subcutaneous xenografted nude mice models of human gastric cancer were established. Subsequently, biodistribution and photothermal therapeutic effects after being intravenously injected with the prepared nanoprobes were assessed. Photoacoustic imaging revealed that CD44v6-GNS nanoprobes could target the gastric cancer vascular system actively at $4 \mathrm{~h}$ post-injection, while the probes inhibited tumor growth remarkably upon NIR laser irradiation, and even extended survivability of the gastric cancer-bearing mice. The CD44v6-GNS nanoprobes exhibited great potential for applications of gastric cancer targeted imaging and photothermal therapy in the near future.
\end{abstract}

Key words: gold nanostars; CD44v6 monoclonal antibody; gastric cancer stem cells (GCSCs); photoacoustic imaging; photothermal therapy

\section{Introduction}

Gastric cancer (GC) is the fifth commonest cancer and the third leading cause of cancer-related mortality worldwide [1, 2]. It ranks third among all malignant tumors in China according to the latest cancer disease spectrum [3]. The prognosis for GC is very poor with 5-year survivals below 24\% [2]. Multidisciplinary treatment is used to improve treatment efficacy of advanced stage GC [4]. However, it has been shown that GC is not particularly sensitive to traditional therapies, especially to chemotherapy agents, which seems to be closely related to numerous intrinsic or acquired properties of cancer stem cells (CSCs) $[5,6]$. 
Despite the hypothesis of CSCs being challenged, growing evidence has been provided to support the existence of CSCs. The notion that CSCs give rise to GC and may be responsible for invasion, metastasis, and resistance to conventional treatment has profound implications for anti-cancer targeted therapies [7]. Current therapies are palliative designed to reduce tumor size, relieve symptoms, and increase survival times temporarily, but hardly can cure cancer thoroughly. How to exert a radical cure in GC has become a great challenge. To date, an increasing number of preliminary studies have demonstrated that tumors are a type of stem cell disease and they contain a few cells known as cancer stem cells or cancer-initiating cells (CSC/CIC), which have been defined according to their abilities to recapitulate the generation of a continuously growing tumor [8] and repopulate the cancer when the bulk of the tumor tissue is wiped out by anticancer drugs [9]. Although the existence of CSCs in tumor tissues still remains as a controversial point, the CSC hypothesis is extremely attractive because it provides a conceptual framework on which new therapeutic approaches could be built; i.e., any drugs capable of killing CSCs would, in theory, be curative. Therefore, CSC-based targeted therapy is destined to be one of the most effective anticancer strategies [5].

CSC-related investigations highly depend on appropriate CSC isolation and enrichment methods. The current strategies for CSC isolation and enrichment include those methods based on stem cell surface markers [10, 11], autofluorescence [12], spheroid colony formation [13], the identification of side population cells [14], resistance to cytotoxic compounds [15] or hypoxia, and invasiveness [16, 17]. CSCs are mostly defined by the expression of CSC-markers that are associated with the potential to grow xenografts in mice. The biomarker profiles have been elaborated for many tumors, with several markers, such as CD24, CD44, CD133, CD166, EpCAM, and some integrin molecules, being over-expressed in tumors of different histological types [18]. With several molecules having been used in tumor targeted therapy, a few promising therapeutics have been developed in preclinical trials [19]. So far, three kinds of molecular markers, such as CD24, CD54, and CD44, have been identified to be closely associated with human GC, and they were successfully used to isolate and screen out GCSCs from the initial cell mass group, tumor tissues and even peripheral blood [17, 20, 21].

CD44, as an adhesion/homing molecule, is a transmembrane glycoprotein and surface receptor for hyaluronan (HA). It was first identified as a GCSC surface marker by Takaishi, et al. [11]. Chen, et al. identified a subpopulation of CD44+ cells within the tumor tissues from GC patients that were endowed with stem cells properties [22]. In addition, the gastric cancer stem-like cells (CSLCs) isolated from the vincristine-preconditioned SGC7901 cell line also displayed increased expression of CD44 mRNA levels [15]. CD44 is involved in the response of cells to their microenvironment, which is crucial to tumor cell behavior, such as survival, progression, and metastasis [23]. These malignant behaviors are associated with CSC properties. Undoubtedly, it made CD44 an attractive target for antibody-guided therapy, HA-conjugated drugs, nanocarrier delivery systems, or linked to radioactive isotope or chemotherapeutic agents [24, 25], which could actively target to CD44, inhibit and disrupt CD44-matrix interactions, influence CD44 signaling and cause apoptosis. With respect to the use of CD44 variant isoforms, especially CD44v6-specific antibodies for cancer therapy in GCSC and GC, it appears to be an attractive indication due to high expression frequencies of the CD44v6 in GC cell lines, primary tumors, and lymph node metastases. Moreover, CD44v6 have a much more restricted distribution in vivo compared to CD44 [25]. Several versions of CD44v6-specific antibodies have been tested in clinical phase I trials, which showed excellent tumor targeting and a favorable biodistribution [26, 27]. Therefore, based on the interference between CD44v6 and its ligand interactions, targeted therapy should be very effective to act on GCSCs, inhibiting local tumor growth and metastatic spread [28].

Nanotechnology makes an important contribution towards cancer prevention, diagnosis, imaging, and treatment [29]. It not only provides unprecedented capability for carrying multiple diagnostic and therapeutic payloads $[30,31]$ in the same package, but also facilitates targeting delivery into specific sites across complex biological barriers. The multifunctional integrated system combines different properties such as tumor targeting, imaging and selective therapy in an all-in-one system, which will provide more useful multimodal approaches in the battle against cancer. Gold nanostars (GNSs), as one kind of emerging nanomaterial, have been actively investigated as an application in nanomedicine, including surface-enhanced Raman scattering, photoacoustic imaging in lymphangiography [32], photodynamic therapy (PDT) [33], and photothermal therapy (PTT) [34]. Nevertheless, few studies have used GNSs as theranostic agents in the imaging and therapy of GCSCs.

Herein, we selected CD44+ GCSCs as the research target and prepared CD44v6 monoclonal antibody-conjugated PEG-modified GNS nanoprobes. The feasibility of using the prepared nanoprobes as 
theranostic agents for targeted photoacoustic imaging and photothermal therapy of GCSCs was investigated. The developed multifunctional nanoprobes were characterized via different techniques, including TEM, SEM, EDX, DLS and the UV-Vis spectrum. The cytotoxicity, cellular affinity, and endocytosis of the nanoprobes were evaluated. Additionally, the developed CD44v6-GNS were used as nanoprobes for photoacoustic, infrared microscopic imaging, and photothermal therapy. Our results demonstrated that the prepared CD44v6-GNS could successfully target GCSCs, and manifest great potential in applications of targeted imaging and selectively therapy as well as preventing the recurrence of GC in the near future.

\section{Materials and Methods}

\subsection{Synthesis and characterization of GNSs}

The synthesis and characterization of surfactant-free GNSs were first presented by Hsiangkuo Yuan et al. [35]. Based on this method, citrate gold seeds were prepared by adding $15 \mathrm{~mL}$ of $1 \%(\mathrm{w} / \mathrm{v})$ trisodium citrate to $100 \mathrm{~mL}$ of boiling $\mathrm{HAuCl}_{4}(1 \mathrm{mM})$ under vigorous stirring for $15 \mathrm{~min}$. A wine-red solution was obtained (12 $\pm 0.7 \mathrm{~nm}$; A520: 3.1), as shown in Supplementary Fig. S1A. The solution was cooled and filtered using a $0.22-\mu \mathrm{m}$ nitrocellulose membrane, and then kept at $4{ }^{\circ} \mathrm{C}$ for long-term storage. GNSs were prepared using a seed-mediated method by quickly mixing $\mathrm{AgNO}_{3}(1 \mathrm{~mL}, 3 \mathrm{mM})$ and ascorbic acid $(0.5$ $\mathrm{mL}, 0.1 \mathrm{M})$ together into $102 \mathrm{~mL}$ of $\mathrm{HAuCl}_{4}(100 \mathrm{~mL}$, $0.1 \mathrm{mM})$ containing $\mathrm{HCl}(1 \mathrm{~mL}, 1 \mathrm{M})$ and citrate gold seeds $(1 \mathrm{~mL}$, OD520 $=3.1)$ under moderate stirring. The color of the solution turned from light red to greenish-black rapidly within $30 \mathrm{~s}$. PEGylated GNSs were prepared by adding final $5 \mu \mathrm{M}$ of hetero-bi-functionalized PEG (Thiol-Poly(Ethylene Glycol)-Carboxymethyl MW: $5000 \mathrm{Da}$ ) to freshly synthesized GNS for $2 \mathrm{~h}$, gentle stirring was followed by one centrifugal $(10,000 \mathrm{~g}, 15 \mathrm{~min})$ wash, and then resuspended in deionized water.

\subsection{Preparation of CD44v6-monoclonal anti- body-conjugated GNSs}

3-(3-dimethylaminopropyl)-carbodiimide (EDC, $2 \mathrm{mM}$ ) and N-hydroxysulfosuccinimide (Sulfo-NHS, 5 $\mathrm{mM}$ ) were added to $1 \mathrm{~mL}$ of the PEGylated GNSs solution (keeping the solution at $\mathrm{pH}$ 6.0), mixing the reaction components well and reacting for $15 \mathrm{~min}$ at room temperature. Then $\mathrm{pH}$ was adjusted to 7.0 and $15 \mu \mathrm{L}$ mouse anti-human CD44/CD44v6 antibodies (BD Biosciences, USA) were added to the above reaction solution. Lastly, the reaction was allowed to proceed for $2 \mathrm{~h}$ at room temperature under constant stirring and strict protected from light. A quenching reagent (glycine, $40 \mathrm{mM}$ ) was added to terminate the reaction. After two centrifugation washes $(20,000 \mathrm{~g}$ for $15 \mathrm{~min}), \quad \mathrm{CD} 44 / \mathrm{CD} 44 \mathrm{v} 6$-antibody-conjugated PEG-GNSs (GNS-PEG-CD44/CD44v6) were dispersed in $1 \mathrm{~mL}$ PBS ( $\mathrm{pH}$ 7.4). The coupling rate of anti-CD44/CD44v6 monoclonal antibodies with gold nanostars was estimated by NanoDrop 1000 device (Thermo Scientific, Wilmington, DE, USA). The total concentration of monoclonal antibodies was measured before the coupling reaction. After coupling with gold nanostars, we estimated its concentration in the eluenting phase of centrifugation and calculated the coupling rate according to the following equation: coupling rate $(\%)=(1-$ amount of monoclonal antibodes in eluenting phase/total amount of monoclonal antibodies) $\times 100$. The acquired solution was filtered using a $0.22-\mu \mathrm{m}$ nitrocellulose membrane and then kept at $4{ }^{\circ} \mathrm{C}$. The absorbance, morphology and energy dispersive X-ray (EDX) analysis of the prepared nanoparticles were evaluated by Varian Cary $50 \mathrm{UV}$-Vis spectrophotometer, high-resolution transmission electron microscope (JEOL, JEM-2010) and field emission scanning electron microscopy (FESEM, Zeiss Ultra), respectively. Dynamic light scattering (DLS) measurements were performed under a Malvern Zetasizer 3,000 HS (Malvern Instruments, Ltd.) equipped with a $125 \mathrm{~mW}$ laser light and operated at $\lambda$ $=633 \mathrm{~nm}$. All samples were measured at a scattering angle of $90^{\circ}$. The zeta potentials $(\zeta)$ of GNSs in PBS buffer $(\mathrm{pH}=7.4)$ were measured on the Malvern Zetasizer Nano $\mathrm{S}$ at $25^{\circ} \mathrm{C}$. The cuvette was filled with the sample solution and the measurement was performed in the $\zeta$-model for a minimum of 10 cycles and a maximum of 100 cycles.

\subsection{Characterization and isolation of GCSCs (CD44+ cell subset)}

The human gastric cancer cell line MKN-45 was purchased from American Type Culture Collection (Manassas, VA, http://www.atcc.org). It was chosen for research on GCSCs in numerous studies [11, 36, 37] in which the sorted cells from MKN-45 were examined and demonstrated stem cell-like characteristics. Moreover, MKN-45 demonstrated significant tumorigenicity in vivo and greater resistance to radiotherapy compared with other cell lines [11], which seemed to be closely similar to the characteristics of GCs prone to metastasis, recurrence, and resistance to conventional treatment. CD44-expressing GCSCs have been identified as stem-like cells for molecular imaging and targeting the key metabolic enzymes to overcome therapy resistance in GC $[36,37]$. The cell culture media was supplemented with $10 \%$ fetal bovine serum (FBS), 89\% RPMI-1640 medium, and 1\% of penicillin-streptomycin. $70-80 \%$ confluent cells in a 
$100-\mathrm{mm}$ cell plate (2-3 million cells per plate) were washed three times with phosphate-buffered saline, and then the cells were dissociated from the plates using trypsin and centrifuged (800 rpm, $2 \mathrm{~min})$. Cell pellets were resuspended in PBS buffer containing $2.5 \%$ FBS and incubated with the following antibodies: mouse anti-human CD44-FITC antibodies (BD Biosciences) and mouse anti-human CD44v6-FITC antibodies (BD Biosciences) for $30 \mathrm{~min}$, Meanwhile, an isotype nonspecific IgG group was set as a blank control, followed by washes with PBS containing 2.5\% FBS two times to remove unbound antibodies. Then they were detected by flow cytometry. The results were analyzed using software FlowJo version 7.6.1. To check their capability of forming spheroid bodies, GC-CD44+ cell subset and GC-CD44- cell subset were cultivated separately in a serum-free medium supplemented with RPMI-1640 medium (hyclone) containing $10 \mathrm{mM}$ HEPES, B27 (1 mL/50 mL medium), EGF $(20 \mathrm{ng} / \mathrm{mL})$, and bFGF $(10 \mathrm{ng} / \mathrm{mL})$. For FACS cell sorting, 5-10 million cells that were collected were stained by mouse anti-human CD44-FITC antibodies as described earlier and sorted by MoFlo XDP (Beckman coulter Company).

\subsection{Spheroid colony formation assay}

FACS-sorted MKN-45 GC cells, both CD44+ and CD44-, were inoculated in each well (10 cells per well) of ultra-low attachment 96-well plates supplemented with $200 \mu \mathrm{L}$ serum-free medium respectively. After four weeks, each well was examined using light microscopy and total well numbers with spheroid colonies were counted. Images of the spheroid colonies were recorded using an inverted microscope.

\subsection{Cytotoxicity of the probes}

The cytotoxicity of GNSs, GNS-PEG, and GNS-PEG-CD44v6 for GC CD44+ cells were evaluated by a colorimetric assay, based on the cellular reduction of WST water-soluble tetrazolium2-(2-methoxy-4-nitrophenyl)-3-(4-nitrophenyl)-5-( 2,4-bisulfophenyl)-2H-tetrazolium salt (Cell Counting Kit, Beijing Fanbo Biochemicals, China) in metabolically active cells. In the cell viability experiment, GC CD44+ cells $(5,000$ cell/well $)$ were seeded into 96-microwell plates and incubated at $37^{\circ} \mathrm{C}$ for $6 \mathrm{~h} .10$ $\mu \mathrm{L}$ of GNS-PEG and GNS-PEG-CD44V6 with different concentrations $(200,100,50,25$ and $12.5 \mu \mathrm{g} \mathrm{Au} / \mathrm{mL})$ were added to the serum-fresh medium in 96-microwell plates respectively. After $24 \mathrm{~h}$ incubation, $10 \mu \mathrm{L}$ CCK solution was added to each well. The cell viability was calculated according to the equation: cell viability $=\left(\mathrm{OD}_{490} \mathrm{~nm}\right.$ of the experimental group/OD $490 \mathrm{~nm}$ of the control group) $\times 100 \%$ and the cell viability of control group was denoted as $100 \%$.
Normal gastric mucosa epithelial cells GES-1 were set as a control.

\subsection{Endocytosis of GNS-PEG and GNS-PEG-CD44v6}

GC CD44+ $\left(1 \times 10^{5}\right)$ cells were cultured in T-25 flasks in serum-free medium to form spheroid colonies. Before the GNS-PEG, and GNS-PEG-CD44v6 challenge, coverslip-bottomed 24 well plates were coated with poly-D-lysine-hydrobromide (PDL coating concentration: $0.1 \mathrm{mg} / \mathrm{mL}$, Beyotime Biotechnology, China). GC-CD44+ cells were seeded at 50 colonies/well in 24-well tissue culture plates for $4 \mathrm{~h}$ and then incubated with GNS-PEG and GNS-PEG-CD44v6 (final concentration, $1 \mu \mathrm{g} \mathrm{Au} / \mathrm{mL}$ ) for $2 \mathrm{~h}$ and $24 \mathrm{~h}$ at $37^{\circ} \mathrm{C}$, respectively. The treated spheroid colonies were washed gently three times with PBS ( $\mathrm{pH} 7.4$ ) to eliminate unbound nanoparticles. To observe the binding affinity and endocytosis of the nanoparticles with GC CD44+ spheroid colonies, light-scattering images were recorded using a dark-field microscope (Olympus BX61TRF) with a high numerical aperture dark-field condenser (Olympus). To further evaluate the targetability of GNS-PEG-CD44v6, the cellular affinity of GNS-PEG-CD44v6 to CD44- cells had also been examined. Additionally, the functionalized GNS-CD44v6 were incubated with the CD44+ subset at $4{ }^{\circ} \mathrm{C}$ for $24 \mathrm{~h}$ to prevent internalization, and pre-incubation of anti-CD44v6Ab before treating CD44+ subset cells with GNS-CD44v6 were used as a control for non-internalized nanoparticles. Endocytosis and distribution of the probe within cells were also examined by $120 \mathrm{KV}$ B-TEM (Tecnai G2 Spirit Biotwin, FEI). The adherent MKN-45 cells were set as controls.

\subsection{Photothermal therapy of GCSCs under $790 \mathrm{~nm}$ NIR laser irradiation}

The photothermal effect of GNS was examined by digital thermometer (Agilent) before application in vitro and in vivo. Based on the existing experimental condition, the NIR-induced heat conversion between gold nanorods and gold nanostars were also compared at the same concentration.

GC CD44+ spheroid colonies (50 colonies / well) were cultured in PDL-coated 24 well plates for $4 \mathrm{~h}$. Then the cells were incubated with GNS-PEG and GNS-PEG-CD44v6 (final concentration, $1 \mu \mathrm{g} \mathrm{Au} / \mathrm{mL}$ ) at $37^{\circ} \mathrm{C}$ for $24 \mathrm{~h}$. Note that all cells were washed with PBS ( $\mathrm{pH} 7.4$ ) three times to ensure the removal of the excess probe from the solution, and then replaced with fresh medium before exposure to NIR laser light. For laser irradiation experiments, cells were exposed to a NIR coherent fiber diode laser $(790 \mathrm{~nm})$ to induce photothermal cell damage. The focused spot region 
was adjusted to $2 \mathrm{~mm}$. Different powers of photothermal treatment were acquired by adjusting the electric current of the laser. Subsequently, the treated cell populations were exposed to $790 \mathrm{~nm}$ NIR laser for 5 min with five different intensities $(15,10,3,1.5,0.3$ $\left.\mathrm{W} / \mathrm{cm}^{2}\right)$. Meanwhile, morphological changes of GC-CD44+ spheroid colonies were observed by inverted microscopy after photothermal ablation treatment. The colonies that had not been incubated with nanoprobes were set as blank controls simultaneously. Then quantitative assays were performed to accurately evaluate cell viability and to further determine the optimized laser intensity for photothermal therapy in vitro. The cells were seeded in 96-well plates with a density of five colonies/well, which had been incubated with the GNS-PEG-CD44v6 at the same final concentration of $1 \mu \mathrm{g} / \mathrm{mL}$ and washed to remove the unbound probe. Then the cells were or were not exposed to NIR laser irradiation with different power densities $\left(0.3,0.6,0.9,1.2,1.5 \mathrm{~W} / \mathrm{cm}^{2}\right)$. After the cells were incubated for another $24 \mathrm{~h}$, each well was incubated with CCK solution for $4 \mathrm{~h}$. Cell viability was calculated by the percentage of OD value for the research group over the control group.

\subsection{Establishment of xenografted tumor models of gastric cancer}

All animal experiments were approved by the Institutional Animal Care and Use Committee of Shanghai Jiao Tong University. The orthotopic and subcutaneous xenografted tumor models of GC in nude mice were prepared. Nude mice (6- to 8- weeks old) were obtained from the Shanghai SLAC Laboratory Animal Co. Ltd., and housed in a SPF-grade animal center. $1 \times 10^{6}$ GC MKN-45 cells/site were injected subcutaneously to establish the subcutaneous tumor models of GC. After about four weeks, the mice were anesthetized and the tumors were excised surgically. The tumor tissue was further cut into fragments with a diameter of $0.1 \mathrm{~cm}$. Subsequently, the nude mice were anesthetized and a left paramedian abdominal incision was made. The stomach was drawn out gently, and a slight incision was made with surgical scissors on the gastric serosal surface. Medical adhesive was applied to cover the incision and one piece of the tumor fragment was placed over the incision quickly. When the gum formed, the stomach was returned to its position in the body and the incision was closed. Fourteen days later, the GC orthotopic models were formed. All steps were carried out aseptically.

\subsection{Infrared microscopic imaging and photo- thermal ablation of GCSCs}

To examine the photothermal effect and biodis- tribution of nanoparticles, GC tumor-bearing mice were intravenously injected with $150 \mu \mathrm{L}$ GNS-PEG and GNS-PEG-CD44v6 (0.867 $\mathrm{mg} \mathrm{Au} / \mathrm{mL})$ respectively. The temperature variation of tumor sites was imaged with a digital high-definition infrared microscopic imaging system (Ying Fu Photoelectric Technology Co. Ltd, Shanghai, China) when exposed to NIR laser irradiation. Forty GC tumor-bearing nude mice were randomly divided into four groups. Each of the three groups received an injection of GNS-PEG-CD44v6, GNS-PEG or PBS (150 $\mu \mathrm{L} /$ mouse) followed by laser irradiation. The concentrations of GNS-PEG-CD44v6 and GNS-PEG were $130 \mu \mathrm{g}$ $\mathrm{Au} / 150 \mu \mathrm{L}$. The fourth group was untreated. Meanwhile the tumor volumes and survival curves of tumor-bearing mice were monitored during treatment.

\subsection{GNS-PEG-CD44v6 nanoprobes for pho- toacoustic imaging of GCSCs}

Photoacoustic (PA) imaging of the probes was accomplished by Endra Nexus 128 PA scanner (Ann Arbor, MI), which is a self-contained shielded unit, containing a laser, acoustic detector, fluid management, and data systems in one cabinet. The laser source of the scanner system, which can achieve an isotropic and homogeneous spatial resolution of 200 microns, operates at 2 to $4 \mathrm{MJ}$ between 680 and 950 $\mathrm{nm}$. The maximum penetration depth is $20 \mathrm{~mm}$ in the mouse skin. Imaging of the GNSs in vitro was originally done in a small tube. Osirix (OsiriX Foundation, Genève, Switzerland) software was used to gain quantitative information in terms of average PA intensity by creating regions of interest (ROIs). Soon afterwards, nude mice with both orthotopic and subcutaneous xenografts were intravenously injected with $150 \mu \mathrm{L}$ GNS-PEG-CD44, GNS-PEG-CD44v6, or GNS-PEG (0.867 $\mathrm{mg} \mathrm{Au} / \mathrm{mL})$. Then the imaged target (tumor) was well mounted in or on the protruding tip of the bowl. The imaged position was kept consistent to facilitate the comparisons. It was imperative that the protruding tip of the bowl was immersed in water and the interface between the slot and imaging target was without bubbles, providing excellent photoacoustic signal transduction. Finally, PA imaging of the imaged target was acquired according to different injection times when it was irradiated by the laser. Pre-injection scans were set as controls. The PA waves were detected by an ultrasound transducer spirally distributed on the surface of the bowl, creating an image of the optical absorption distribution inside the tissues and transmitted to the computer. Single slice 2D and volume 3D photoacoustic data overlaying in co-registered different modes were visualized by Osirix imaging software. 


\subsection{ICP-MS measurement}

Nude mice with GC xenografts were intravenously injected with $150 \mu \mathrm{L}$ GNS-PEG and GNS-PEG-CD44v6 (0.867 mg Au/mL). They were sacrificed at $4 \mathrm{~h}$ and $24 \mathrm{~h}$ post-injection ( $\mathrm{n}=3$ /group). The blood, tumor, heart, liver, spleen, lungs, kidneys, and brains were collected and weighed. The blood and tissues were digested with aqua regia under heating. The gold content in the solution was determined by an Agilent 7500a.

\section{Results and discussion}

\subsection{Preparation and characterization of CD44v6 antibody-conjugated and PEGylated GNS}

The GNS-based PEGylated and CD44v6 antibody-conjugated multifunctional nanoprobes (GNS-PEG-CD44v6) were prepared for targeted PA, X-ray/CT imaging (Supplementary Fig. S2 and Supplementary Fig. S3) and photothermal therapy of GCSCs (Scheme 1). The GNSs were stabilized and chemically functionalized by heterobifunctional polyethyleneglycol (Carboxymethyl-PEG-SH) [38], which could bind with the gold nanoparticles by the oxidative addition of the S-H and connect to the antibodies by the carboxyl group. The nanoprobes were characterized with UV-Vis absorption spectroscopy, FESEM (Fig. 1A and Fig. 1D) and TEM (Fig. 1B and Fig. 1E). The peak position of the surface plasmon resonance (SPR) of GNSs was tunable by the width of base, the diameters of core and tips, the numbers of branches and aspect ratios [35, 39]. The SPR peaks could be shifted to the NIR region by increasing the number of branches. The products synthesized in our study were branched nanoparticles with more than eight branches, in contrast to 3 to 6 , with the absorption band located at about $635 \mathrm{~nm}$ [40]. The high-resolution TEM (HRTEM) image of a single branch (Fig. 1C) of GNSs showed lattice fringes with an average interface distance of $0.22 \mathrm{~nm}$. The selected area electron diffraction (SAED) pattern (Fig. 1F) and lattice fringes of the GNS confirmed that each of the GNSs was multicrystalline.

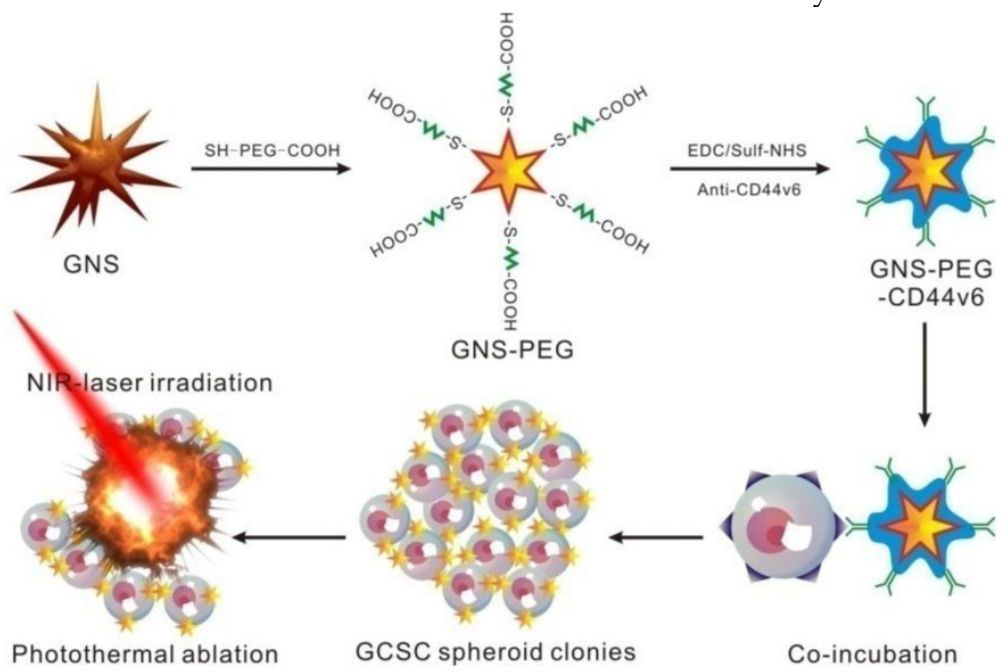

Scheme 1. Schematic illustration of the GNS-PEG-CD44v6 nanocomplex synthesis process and the mechanism of GCSC targeted PTT.
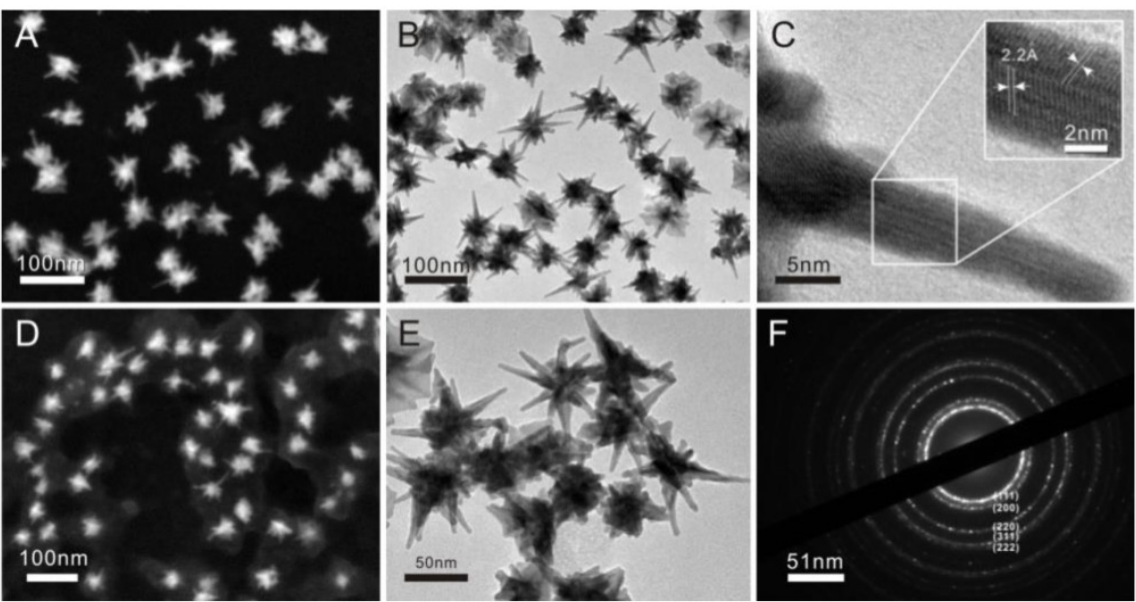

Fig. 1. Representative FESEM (A) and TEM (B and E) images of GNSs; (C) HRTEM images of GNS branchand lattice fringes on a single branchtip; (D) FESEM image of PEG-encapsulated GNSs; (F) Diffraction spectrum image of GNS. 
In this study, anti-CD44 and anti-CD44v6 monoclonal antibodies were conjugated to the multi-branched GNSs to evaluate the specific cellular affinity between the nanoprobes and GCSCs. The coupling rates of anti-CD44/CD44v6 monoclonal antibodies were $71.9 \%$ and $72.7 \%$, respectively. The GNSs showed a plasmon absorption band at $833 \mathrm{~nm}$, while the absorption peak exhibited a slight red shift to 858 $\mathrm{nm}$ and $846 \mathrm{~nm}$ after encapsulating with PEG and coupling with antibodies (Fig. 2C). The naked GNSs became agglomerate soon and difficult to resuspend after centrifugation, without encapsulated with PEG. Therefore, the dynamic light scattering (DLS) measurement was hardly possible. The average hydrodynamic diameters of GNS-PEG and GNS-PEG-CD44v6 were $89.5 \mathrm{~nm}$ and $92.1 \mathrm{~nm}$, respectively (Fig. 2A-B). The $\zeta$-potential increased from $-46.9 \mathrm{mV}$ (GNS-PEG) to $-12.3 \mathrm{mV}$ (GNS-PEG-CD44v6). The EDX spectroscopy of the GNS-PEG-CD44v6 is shown in Fig. 2D, indicating that PEG had been connected to the GNSs.

\subsection{Isolation and Characterization of CD44+ GCSC cells}

CD44 has been identified as a potential marker of GCSCs. The CD44+ GC cells sorted from MKN-45 showed stem-cell properties, including self-renewal ability and tumorigenicity [11]. MKN-45 showed high level expression of CD44, up to $98 \%$. The expression rate of human CD44v6 was $97 \%$, which was slightly lower than the expression ratio of CD44 molecule
(Fig.3A-B). CD44 family contains standard form (CD44s) and isoforms (CD44v). Interestingly, CD44 isoforms, especially CD44v6, were found to comprise the major portion in CD44 family in GCs according to previous reports $[26,27]$ and our analysis results from flow cytometry. The sorted CD44+ cells can produce spheroid colonies with a diameter of 50 100 $\mu \mathrm{m}$ in serum-free media under non-adherent conditions, while most CD44- cells can't (Fig.3C-F). These CD44+ cells can be cultivated in vitro for more than four weeks, which is considered as the indication of self-renewal ability. Different from Jungmin Park's work in which the CD44-targetable and near-infrared-sensitive supramolecular hydrogels (NIRSHs) were fabricated for fluorescence molecular imaging of stem-like GC cells [36], CD44-expressing spheroid colonies (i.e., GCSCs) were chosen as target cells for evaluation of targeting imaging and photothermal ability of GNS-PEG-CD44v6 in our study.

\subsection{Assessment of cytotoxicity of GNSs in vitro}

A standard MTT colorimetric assay was performed to assess the potential deleterious effect of GNS-PEG and GNS-PEG-CD44v6 towards GES-1 and GCSCs after co-incubation for $24 \mathrm{~h}$. Both GNS-PEG and GNS-PEG-CD44v6 exhibited low cytotoxicity at doses up to $200 \mu \mathrm{g} / \mathrm{mL}$ (Fig. $4 \mathrm{~A}-\mathrm{B}$ ). The excellent biocompatibility was due to the CTAB-free green synthesis of GNSs and the encapsulation of PEG.

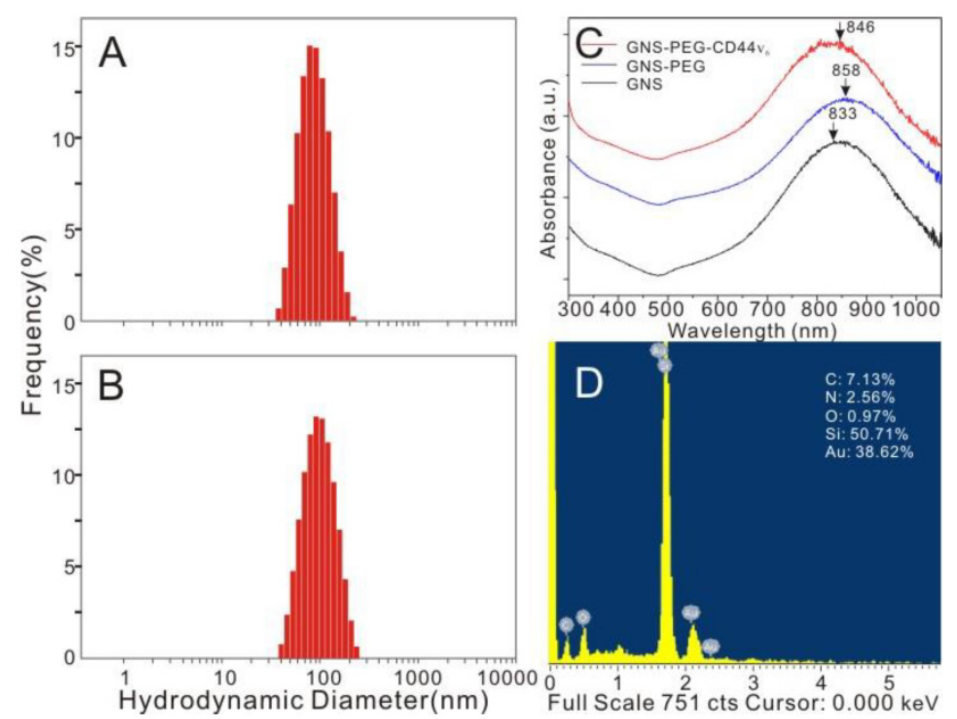

Fig. 2. Characterization of plasmonic-resonant GNSs: (A and B) The average hydrodynamic diameter of GNS-PEG and GNS-PEG-CD44v6; (C) UV-Vis-NIR spectra of GNSs (black line), GNS-PEG (blue line) and GNS-PEG-CD44v6 solution (red line), with an absorption peak at $846 \mathrm{~nm}$; (D) The EDX spectroscopy of the GNS-PEG-CD44v6 by TEM. 

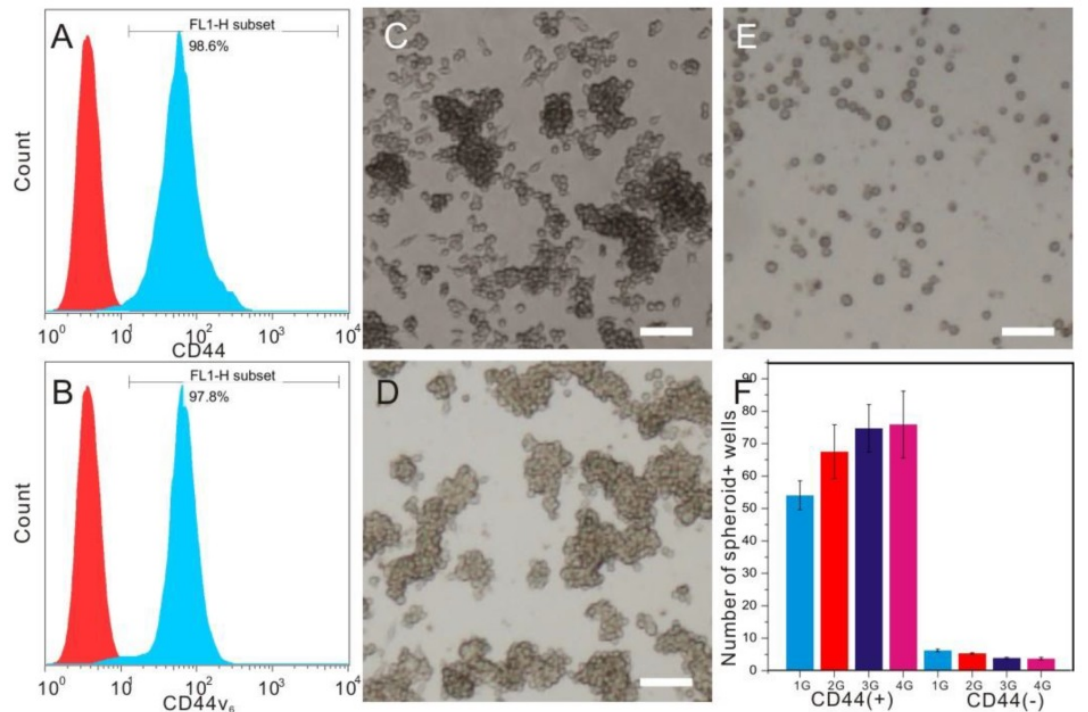

Fig. 3. Fluorescence-activated cell sorter (FACS) analysis of candidate surface markers for GCSCs. Horizontal axis: FITC-CD44 (A) / FITC-CD44v6 (B); Vertical axis: count; inverted microscope images of CD44+sphere cells in different generations ( $C$ and D, 1st generation and 3rd generation) and CD44-sphere cells (E) in the 3rd generation; $(F)$ spheroid colony formation assay between CD44+ cells and CD44- cells in four generations.
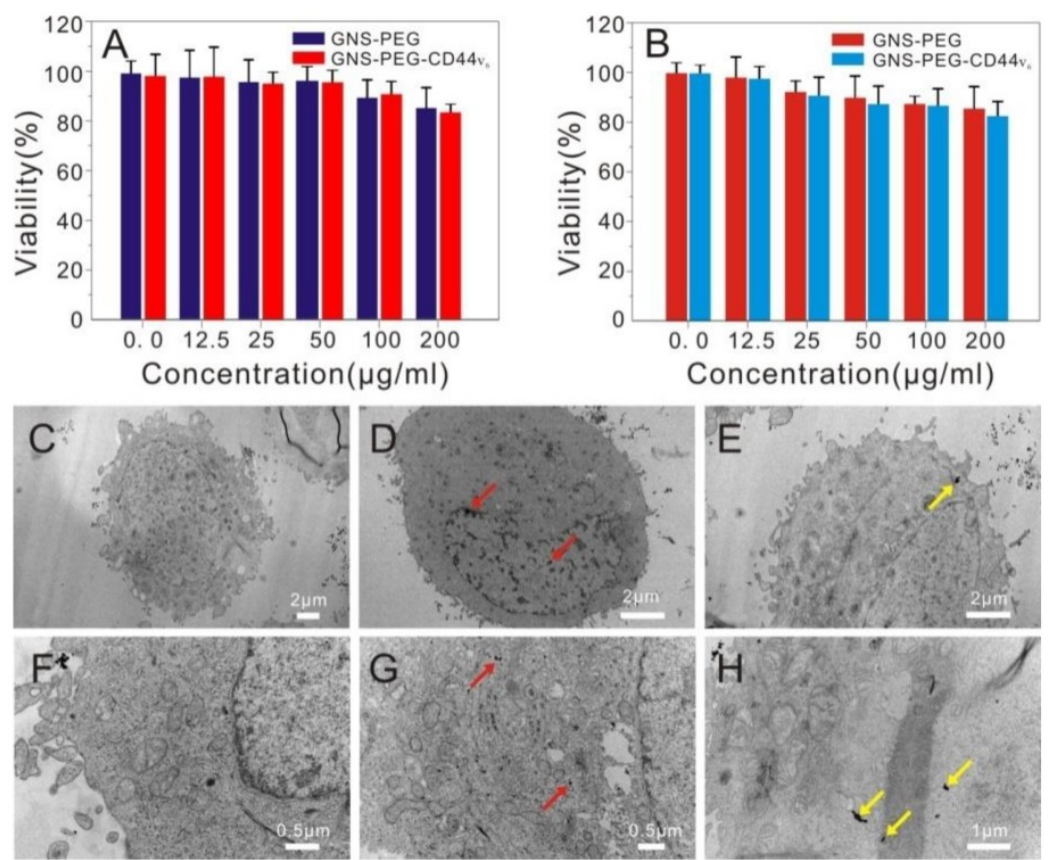

Fig. 4. Viability of GCSCs (CD44+sphere cells) (A) and GES-1 cells (B) treated with GNS-PEG or CD44-targetable GNS-PEG-CD44v6 measured by MTT assay; TEM images of GCSCs treated with GNS-PEG (C, F) and GNS-PEG-CD44v6 (D, G); The arrow indicates that the nannoparticles are mainly gathered in the cytoplasm and nucleus cleft of CD44+sphere cells $(D, G)$ and $G C$ cells $(E, H)$.

\subsection{Internalization of GNS-PEG and GNS-PEG-CD44v6}

The specific targeting ability of the functionalized nanoparticles towards GCSCs (CD44+ sphere cells) in vitro was first confirmed by using dark field microscopy. As shown in Supplementary Fig. S4A-B, shiny yellow spots were observed in the cell membrane and cytoplasm in the light scattering images of the GCSC sphere colonies incubated with GNS-PEG-CD44v6 for $2 \mathrm{~h}$ and $24 \mathrm{~h}$, which was attributed to the light scattering by GNSs bounding the spheroid colonies. Furthermore, the targeting efficiency was analyzed quantitatively by measuring the $\mathrm{Au}$ content in cells, indicating the internalized $\mathrm{Au}$ content at $24 \mathrm{~h}$ was much higher than at $2 \mathrm{~h}$. After incubating with GNS-CD44v6 for $24 \mathrm{~h}$, the treated cells were collected and washed to remove the unlabeled probes. $83 \%$ of the injected dose could be internalized or bound to the cells. However, no evident intracellular uptake and yellow spots could be seen in the control group (bare GNS-PEG), indicating that the nanoparticles had not been attached to CD44+ GCSC 
sphere colonies or endocytosed into cells. The lack of specificity of bare GNS-PEG can explain this phenomenon.

The CD44- cells did not show specific binding for GNS-CD44v6 for the negative controls. These results indicated that GNS-PEG-CD44v6 targeted CD44+ cells specifically without non-specific binding. For the CD44+ subset cells incubated with GNS-PEG-CD44v6, the binding efficiency was decreased to background levels with few shiny yellow dots detected after pre-incubation with anti-CD44v6, which made the receptor binding sites occupied, thus affecting the binding and internalization of GNS-CD44v6. In contrast, GNS-PEG-CD44v6 could be rarely internalized into the cells but accumulated on the cell surface when incubated with CD44+ cells at $4^{\circ} \mathrm{C}$ (Supplementary Fig. S4). From the dark field images, it could be concluded that anti-CD44v6 conjugated gold nanostars manifested a highly specific interaction with the CD44+ subset cells, which made it accessible for the accumulation of the gold nanostars into CD44+ targeted cells.

The cellular uptake of GNS-PEG and GNS-PEG-CD44v6 was also observed by TEM, and similar results were obtained. Little uptake by the GCSC spheres could be seen when incubating with GNS-PEG (Fig. 4C and Fig. 4F), which was mainly attributable to the negative charge and the PEG chains present on the surface of the nanoparticles working as a protective shield layer against non-specific interactions. GNS-PEG-CD44v6 are scattered in the cytoplasm and a mere portion was distributed in the cell membrane and nucleus cleft. (Fig. 4D-E and Fig. 4G-H). Furthermore, the nanoprobes could be absorbed by receptor-mediated endocytosis. All the results confirmed that the GNS-PEG-CD44v6 probe could identify and target CD44+ GCSC sphere colonies actively, facilitating localized cell ablation by directed NIR laser irradiation treatment.

In order to target the key metabolic enzyme or promote rapid membrane permeabilization and necrosis of CSCs, a series of methods have been introduced for systematic treatment, including using an activating monoclonal antibody directed to the adhesion molecule CD44 [41], induction of tumor stem cell differentiation [42], gold nanorods (GNR) or nanotube-mediated thermal treatment [37]. Undoubtedly, nanoparticle-mediated photothermal therapy is one of the most effective therapeutic methods, which is aiming to make tumors lose their long-term proliferative capacity and invasive potential.

\subsection{In vitro targeted photothermal ablation of GCSCs with exposure to NIR laser}

The temperature variation of GNS-PEG-CD44v6 solutions exposed to laser irradiation $(\lambda=790 \mathrm{~nm}, 1.5$ $\mathrm{W} / \mathrm{cm}^{2}$ for 5 min; Supplementary Fig. S5) was first estimated to validate the photothermal therapy (PTT) potential of GNS-PEG-CD44v6 towards GCSCs. The temperature of the solution rose rapidly from $28^{\circ} \mathrm{C}$ to $61^{\circ} \mathrm{C}$ within $3 \mathrm{~min}$, which was sufficient to induce cell damage $\left(1.5 \mathrm{~W} / \mathrm{cm}^{2}\right)$ [38]. The temperature could still rise to about $40{ }^{\circ} \mathrm{C}$ when the laser intensity was reduced to $0.3 \mathrm{~W} / \mathrm{cm}^{2}$ (Fig.6A-B). The probe could generate heat upon laser irradiation due to an excellent plasmon absorption band in NIR. By contrast, after irradiating with equal laser intensities in PBS or water, very little temperature changes could be observed (minimal increase within $3^{\circ} \mathrm{C}$ ). Compared with the NIR-induced heat conversion of gold nanostars, the temperature of the gold nanorods solution with the same $\mathrm{Au}$ content rose to about $33^{\circ} \mathrm{C}$ (Supplementary Fig. S5) upon the same power density of laser irradiation $\left(1.5 \mathrm{~W} / \mathrm{cm}^{2}\right)$, which was much lower than the range of temperatures for GNS. The data described above demonstrated the excellent photothermal conversion efficiency of the anisotropic GNS over GNR and that GNS-PEG-CD44v6 could be an excellent nanoprobe for GCSC PTT.

To demonstrate the feasibility of selectively eradicating CD44+GCSCs by GNS-PEG-CD44v6, CD44+ spheroid colonies were incubated with specific CD44-targetable GNS-PEG-CD44v6 (test group) and GNS-PEG (control group) respectively at $37^{\circ} \mathrm{C}$ for 24 h. Cells were rinsed with PBS ( $\mathrm{pH} 7.4$ ) to remove the unbound probe. After $5 \mathrm{~min}$ of the laser treatment $\left(1.5 \mathrm{~W} / \mathrm{cm}^{2}\right)$, a large portion of the GCSC spheroid colonies were damaged completely (empty area), as shown in Fig. 5. At $0.3 \mathrm{~W} / \mathrm{cm}^{2}$, the colonies became dissociated, scattered and lost the original spheroidal structure (not shown in the article), whereas no obvious change could be observed in the control group because the free floating GNS-PEG that lacked labeling with CD44v6-antibodies could not be concentrated in spheroid colonies and removed by subsequent washing. To further determine the optimized laser intensity for PTT in vitro, cell viability assay was performed for the cells treated with GNS-PEG-CD44v6, which were exposed to NIR laser irradiation with different power densities $(0.3,0.6,0.9$, $\left.1.2,1.5 \mathrm{~W} / \mathrm{cm}^{2}\right)$. The cell viabilities were $94.2 \%, 78.5 \%$, $39.3 \%, 10.8 \%$, and $0.7 \%$, respectively. It is manifested that it could still show toxicity and photothermal ablation effect to the GCSCs with the relatively low power density (Supplementary Fig. S6). 


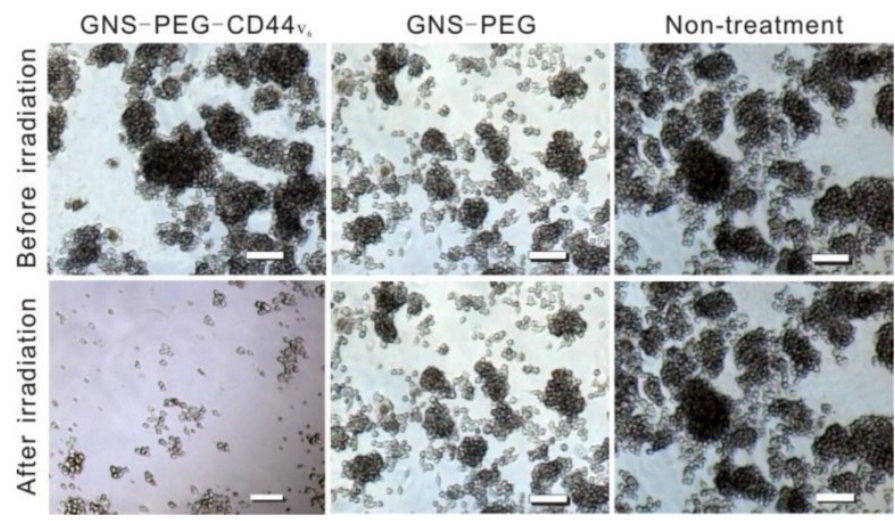

Fig. 5. Microscopy images of GCSC spheroid colonies treated with GNS-PEG and GNS-PEG-CD44v6 for $24 \mathrm{~h}$ after NIR laser irradiation $\left(790 \mathrm{~nm}, 1.5 \mathrm{~W} / \mathrm{cm}^{2}, 5 \mathrm{~min}\right)$. All scale bars are $100 \mu \mathrm{m}$.
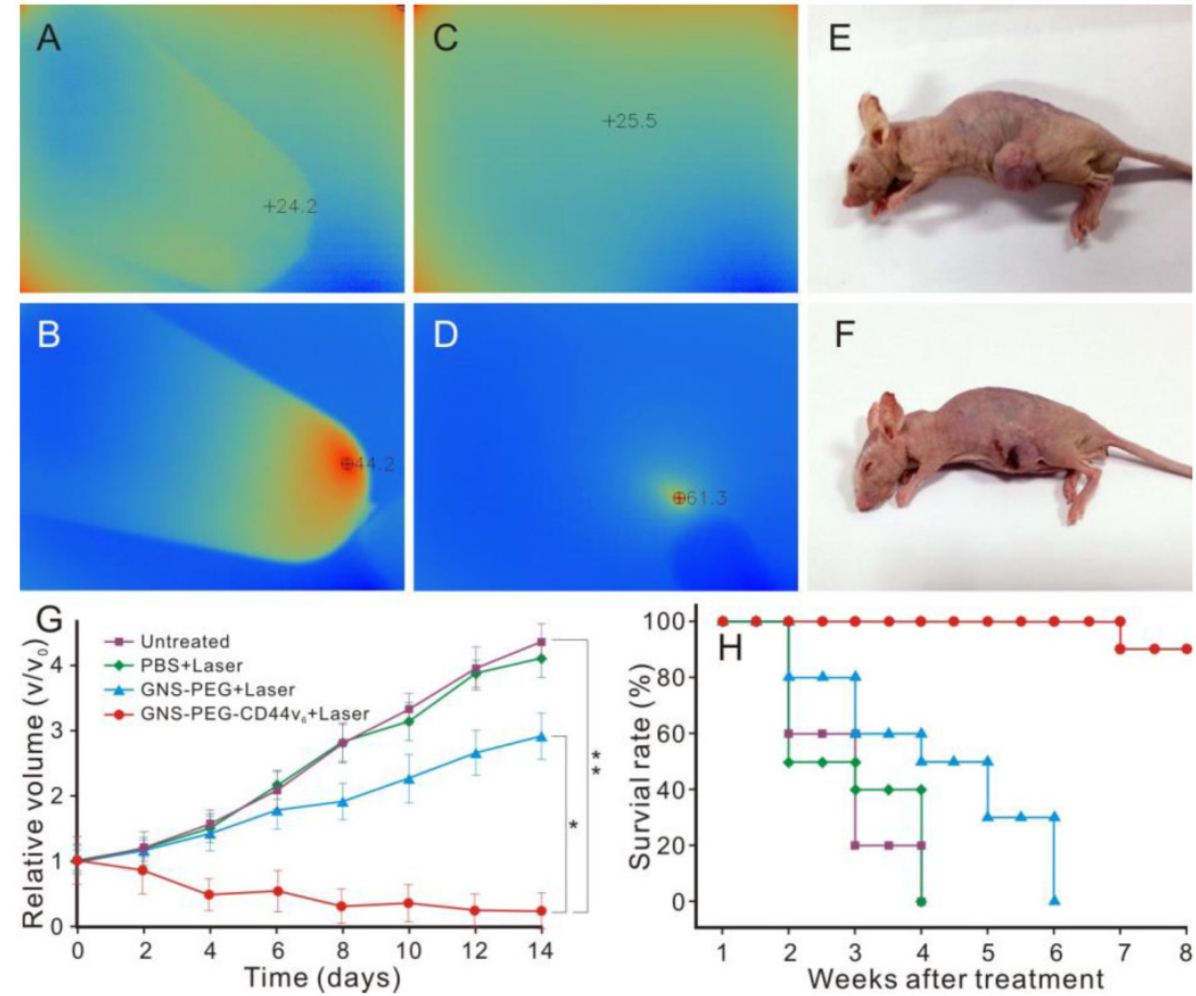

Fig. 6. Infrared microscopic imaging: deionized water (A) and GNS (B) in a tube upon NIR laser irradiation $\left(790 \mathrm{~nm}, 0.3 \mathrm{~W} / \mathrm{cm}^{2}, 3 \mathrm{~min}\right)$; Subcutaneous tumor of GC without (C) and with (D) injection of GNS-PEG-CD44v6 upon NIR laser irradiation $\left(790 \mathrm{~nm}, 1.5 \mathrm{~W} / \mathrm{cm}^{2}, 3 \mathrm{~min}\right)$. The nude mouse of GC subcutaneous xenograft, injected with nanoparticles before $(E)$ and after $(F)$ laser irradiation treatment $\left(790 \mathrm{~nm}, 1.5 \mathrm{~W} / \mathrm{cm}^{2}, 3 \mathrm{~min}\right) ;(\mathrm{G})$ Tumor growth curves of four groups after treatment with GNS-PEG-CD44v6, GNS-PEG and PBS respectively upon NIR laser irradiation $\left(790 \mathrm{~nm}, 0.8 \mathrm{~W} / \mathrm{cm}^{2}, 5 \mathrm{~min}\right)$; and the untreated control group. Error bars represent standard deviation $\left(n=10 /\right.$ group). ${ }^{*} p<0.05,{ }^{* *} p<0.01$, (Student's $t$ test); $(H)$ Survival rate of $G C$ tumor-bearing mice within eight weeks after treatment.

Previous researches had indicated that CSCs are significantly more resistant to the effects of hyperthermia than cancer cells but are sensitive to nanoparticle-mediated PTT [43]. The irradiation intensities in our research were much lower than previously reported for PTT toward CSC [44, 45], while a much lower concentration $(1 \mu \mathrm{g} / \mathrm{mL})$ of the PTT agent was used [44]. The PTT efficiency was also dependent on the concentration of the PTT agent. The higher accumulation of the PTT agent in the cells, the better the treatment effect. In addition, upon the equal laser intensity, the time consumed for PTT was much shorter than in previous reports. In summary, GNS-PEG-CD44v6 is an excellent PTT agent for GCSCs, combining the specific targeting ability with PT transformation efficiency.

\subsection{Infrared microscopic imaging and Photo- thermal ablation of GCSCs}

In vivo NIR absorption infrared microscopic imaging was performed to evaluate the possibility of using GNS-PEG-CD44v6 as a smart imaging probe to detect GCSCs in GC. The subcutaneous tumors in GC xenograft mice were exposed to NIR laser irradiation 
after $150 \mu \mathrm{L}$ GNS-PEG-CD44v6 (0.867 mg Au/mL) were injected. An infrared microscopic imaging system was used to detect the temperature changes of the tumor at different time points. The temperature of the tumor site increased significantly upon laser irradiation in the first $3 \mathrm{~min}$, as shown in Fig.6C-D. Corresponding to the increasing tendency of temperature, the infrared imaging of the tumor changed from blue to red. While, as predicted, no obvious variation of temperature was observed in xenografted mice without injection of nanoprobes or laser irradiation.

Besides the unique NIR absorption characteristics, the GNSs also exhibited strong SPR effective properties. Significantly, the NIR region $(650 \mathrm{~nm}-900$ $\mathrm{nm}$ ) is the transmission window in living organisms [46]. Given the above characteristics, GNS-PEG-CD44 ${ }_{\mathrm{v} 6}$ can be an ideal contrast agent for NIR absorption-infrared microscopic imaging in vivo. With the presence of multiple sharp branches and the high aspect ratio, the GNSs could be a much more effective photothermal transducer than nanospheres and rods [32]. Therefore, it could be used in photothermal ablation treatment for GCSCs in vivo. The enhanced light absorption of the probe in the NIR could promote the effective absorption dose of the targeted tumor tissue. The elevated temperature was high enough to destroy the CD44+ GCSCs in the tumor site. As shown in Fig. 6E, F, necrosis areas existed in treatment center of the tumor tissue irradiated by $790 \mathrm{~nm}$ laser for $3 \mathrm{~min}\left(1.5 \mathrm{~W} / \mathrm{cm}^{2}\right)$ after injection of the prepared nanoprobes. In contrast, there was no palpable change in the NIR absorption-infrared imaging signal and the tumor volume was unchanged without injection of nanoparticles or laser irradiation locally. These results demonstrated that GNS-PEG-CD44v6 can be used as a targeting probe for GCSC photothermal ablation therapy in vivo, due to its excellent photothermal conversion effect and biological compatibility compared with other nanoparticles, such as carbon nanotubes and graphenes $[47,48]$. Therefore, infrared microscopic imaging is a novel and unique imaging technique which could detect both targeting ability and evaluate curative efficacy by temperature changes indirectly.

Based on these results, the higher the laser intensity is, the severer the necrosis would be obtained in the equal time (shown in Fig. 6E-F). However, with the laser intensity increased, the surrounding normal tissue adjacent to the tumor may be affected by the hyperthermal zone, which may highly affect the survivability of the tumor-bearing mice. To optimize the therapeutic effect, we attempted to use lower irradiation power $\left(790 \mathrm{~nm}, 0.8 \mathrm{~W} / \mathrm{cm}^{2}, 5 \mathrm{~min}\right)$, which was performed every two days for two weeks. The accumulation of the nanoprobes in the tumor site could be retained for two weeks [50], which made continued therapy with low power density possible. The 40 GC tumor-bearing nude mice were divided into four groups. Three groups of GC tumor bearing mice received an injection of $150 \mu \mathrm{L}$ of $0.867 \mathrm{mg} \mathrm{Au} / \mathrm{mL}$ GNS-PEG-CD44v6, GNS-PEG, or PBS, followed by laser irradiation $\left(0.8 \mathrm{~W} / \mathrm{cm}^{2}, 5 \mathrm{~min}\right)$ at $4 \mathrm{~h}$ post-injection. The initial gold concentration in the tumor site was $16.64 \mu \mathrm{g}$ and $6.89 \mu \mathrm{g} \mathrm{Au} / \mathrm{g}$, respectively, for GNS-PEG-CD44v6 and GNS-PEG groups at $4 \mathrm{~h}$ after injection with targeted probes. The fourth group was untreated, without laser irradiation. Both the tumor volume and survival curve of each group were monitored during treatment. According to the formula tumor volume $=\mathrm{d} 1 \times(\mathrm{d} 2)^{2} \times 0.5(\mathrm{~d} 1=$ largest diameter, $\mathrm{d} 2$ = perpendicular diameter), the tumor volume was calculated to draw the tumor growth curve. Compared with the control groups, the tumor volumes of GNS-PEG-CD44v6 treated group showed a significant statistical difference and reduced at the end of two weeks of therapy (Fig. 6G).

Targeted ablation of CD44+ stem cells in GC, and destroying the tumor stromal environment by perturbation of HA-CD44 interactions, are the possible reasons for the tumor shrinkage. The GNS-PEG group based on passive targeting therapy exhibited negligible tumor growth inhibition. Meanwhile, there was no obvious therapeutic effect in the untreated group and PBS treated group plus NIR laser. The tumor volume increased even at the end of two weeks of therapy. The survival rate was further recorded for long-term observation of the nanoprobes effect on the tumor. The survivability of mice in the GNS-PEG-CD44v6 treated group was markedly stronger than the control group including GNS-PEG, PBS and the untreated group (Fig. 6H), which demonstrated that the nanoprobes targeting GCSCs can prolong the survival time of tumor bearing mice. Furthermore, for the GNS-PEG-CD44v6 injected groups, similar tumor regression was achieved upon NIR laser irradiation between $1.5 \mathrm{~W} / \mathrm{cm}^{2}$ for one treatment and $0.8 \mathrm{~W} / \mathrm{cm}^{2}$ for two day intervals. While the survival rate and survivability of tumor bearing mice with the former treatment were remarkably lower than the latter, as hadn't been detailed in the research. It may stem from the temperatures of the internal tumor exceeding the tolerance to hyperthermia of the mice (upon laser irradiation of $1.5 \mathrm{~W} / \mathrm{cm}^{2}$ ). The therapy of $0.8 \mathrm{~W} / \mathrm{cm}^{2}$ in two day intervals seems to have been well tolerated for the tumor bearing mice with speculated less severe off-target tissue damage. While a similar scab was observed, due to the shrinkage of the tumor in a short time (two weeks) leading to the formation of incrustation.

Compared with RGD conjugated nanoprobes, 
which target the neovasculature specifically, the synthesized GNS-PEG-CD44v6 multifunctional probe was characterized by analogous effects in targeted tumor destruction $[49,50]$. The relatively low gold concentration applied in our research was attributed to the enhanced tumor delivery and retention by the specific antibodies, high expression frequencies of CD44v6 in both GC cell lines and solid tumors (62.5\% to $87.0 \%$ for CD44v6 in GC cases $[25,26])$, and high photothermal conversion efficiency of the GNS. Additionally, it was also highly correlated with the role of targeted molecular CD44 in GC, which played a major role in tumorigenesis, tumor invasion, and metastasis. The synthetic GNS-PEG-CD44v6 can change the tumor microenvironment, clear CD44-positive GCSCs, and have an influence on tumor initiation and metastatic behavior by interfering with the function of molecular-CD44. Our study is the first attempt to utilize GNS-PEG-CD44v6 nanoprobes for imaging and PTT of GCSCs in vivo.

\subsection{Nanoprobes for photoacoustic imaging of GCSCs in vivo}

PA imaging can be used in a hybrid modality fashion to extend the anatomic and hemodynamic sensitivities of clinical ultrasound. The GNS, an emerging contrast agent, has been selected and applied to photoacoustic tomography noninvasively with its distribution monitored simultaneously [51, 52]. Additionally, the therapeutic response could be quantified by calculating the intensities of PA signals in a timely manner [53]. GNS-PEG-CD44v6 (Fig. 7A) was first synthesized and applied to detect GCSC in PA imaging in both orthotopic and subcutaneous GC xenografted models in vivo. The mice injected with GNS-PEG and GNS-PEG-CD44 were set as controls. The accumulation and distribution of the probe in the tumor were whole-process monitored. Plasmon-resonant nanostars are excellent contrast agents for in vivo photoacoustic tomography, with a detection limit at $1 \mathrm{ppm}(\sim 1 \mu \mathrm{g} / \mathrm{mL})$ [32]. There is a nice linear relationship $\left(R^{2}=0.996\right)$ between the PA signal amplitude and the concentration (Fig. 7B) in vitro. However, it is not between the PA signal amplitude and the excitation wavelength (Fig. 7C). The PA amplitudes reach a maximum at the $950 \mathrm{~nm}$ wavelength, which is not the SPR peak wavelength of the gold nanostars. The PA amplitudes are not consistent with the absorbance curve of the GNS, which is different from the gold nanorods [54]. The discrepancy could be explained by the differences in heat transfer from the particle to the medium and the scattering of light $[55,56]$.

The 720 nm NIR laser with moderate energy ( 4 $\mathrm{mJ}$ per pulse) was used for PA imaging of the tumor in vivo, at which wavelength the neovascularization $(\mathrm{CNV})$ was identified and the probe had a high PA contrast effect. The images displayed with transverse (axial) maximum intensity projection (MIP) and an UCLA modality are shown in Fig.7D. After injection of GNS-PEG-CD44v6 (test group), an increased signal emerged gradually in the first four hours. The vascular system of the subcutaneous tumors could be clearly shown in the fourth hour, but not in the orthotopic tumor, whereas localized reinforcement of the signal could be detected in the stomach area, which remarkably indicated the gradual accumulation of GNS-PEG-CD44v6 in the tumors. A deeper location of the orthotopic tumor and disturbance of the dermal vascular were the possible causes for this phenomenon. During the fourth to sixth hours after injection, GNSs made the vessel signals enhanced and they began to gather in the perivascular spaces and diffuse into the surrounding tissue or even the whole tumor [57]. At $24 \mathrm{~h}$, the signals became slightly faint.

Similar results could also be found after injection of GNS-PEG-CD44, however, the agglomeration effect was weaker than the test group. The reason might be that CD44 is more widely distributed and there is lack of specificity in the tumor site than with CD44 variants. CD44 and its splice variants are positively associated with the initiation, progression of GC and GCSC properties. It could also play important roles in diagnosis, therapy, and prognosis. For the control group (GNS-PEG), there was no remarkable enhancement of the PA signal. Only slight signal enhancement of the intravascular could be observed within 2 4 hours after injection, as shown in Fig. 7D.

To further quantify the PA signals of the tumor site, an identical region of interest (ROI) was selected in each MIP image, which is indicated by a white dashed circle in the first image of Fig. 7D. The trend of the normalized PA signal enhancement over time of the five groups was illustrated (Supplementary Fig. S7). The PA signal reached a peak at $4 \mathrm{~h}$ after injection in the five groups, followed by a decrease at $24 \mathrm{~h}$. In the subcutaneous GC xenografted model, the PA enhancements of the GNS-PEG-CD44v6 group were 4.7-fold higher at $4 \mathrm{~h}$ after injection, compared with 2.5-fold higher in GNS-PEG-CD44 group. In the orthotopic xenografted model, slight enhancements were observed. In contrast, the PA enhancements were 1.75-fold higher at $4 \mathrm{~h}$ after injection in GNS-PEG injected group. Overall, at $4 \mathrm{~h}$ post-injection, enhancement of the GNS-PEG-CD44v6 group was on average $250 \%$ times greater than that with PEG-GNS ( $p<0.05)$, which correlated well with the Au distribution in ICP-MS results, shown in Fig. 8. The distinct difference demonstrated the targeting delivery ability of GNS-PEG-CD44v6 to tumors. 

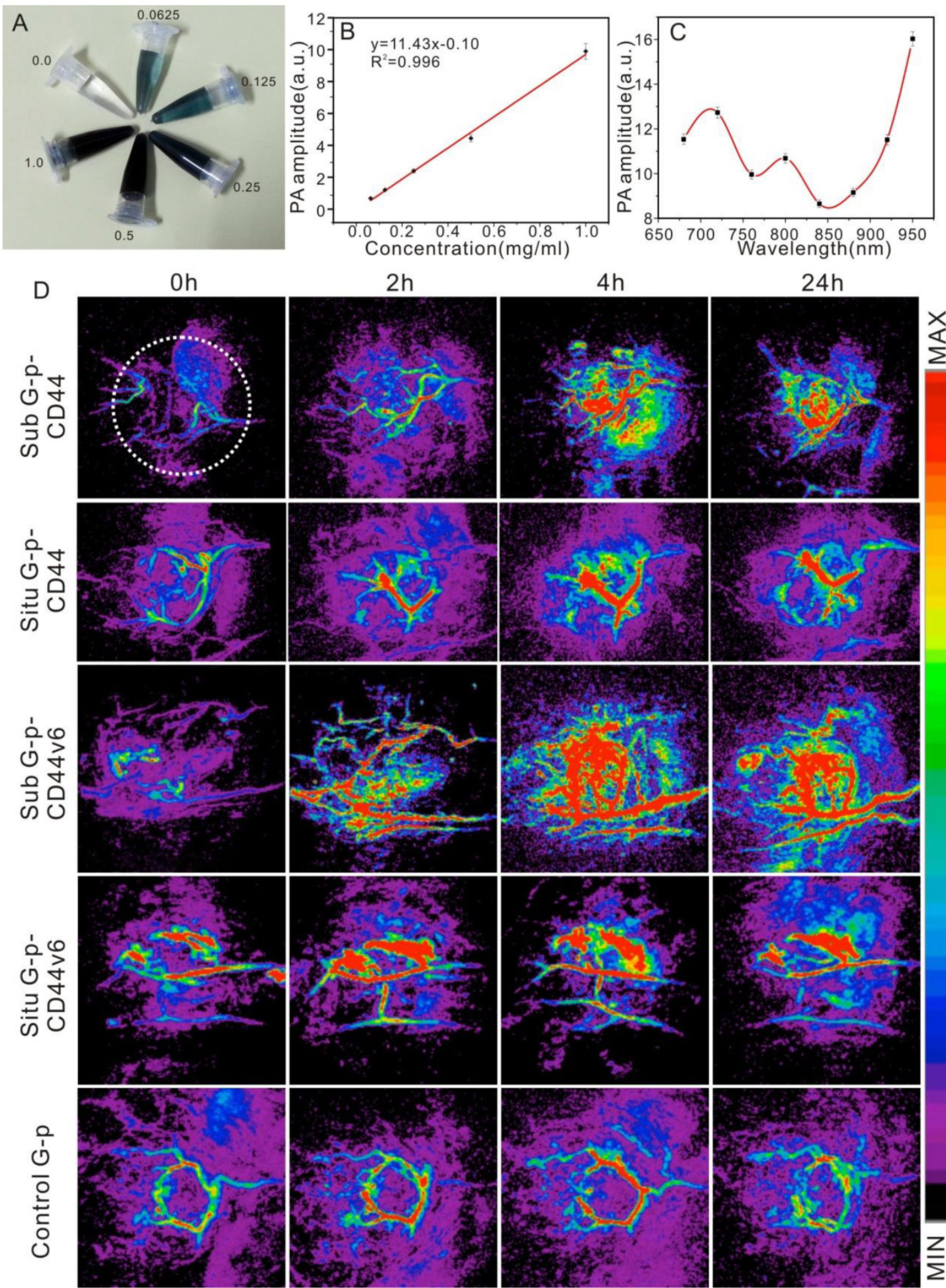

Fig. 7. (A) GNS-PEG-CD44v6 in vitro in the concentration range of $0.0625 \mathrm{mg} / \mathrm{mL}$ to $1 \mathrm{mg} / \mathrm{mL}$; Dependence of PA signals on the nanoparticle concentration (B) and wavelengths $(C)$; The error bars indicate the standard deviation for each measurement $(n=3)$; (D) PA imaging in vivo in the UCLA mold: Representative PA sequential images acquired before injection $(0 \mathrm{~h})$ and after injection $(2,4$, and $24 \mathrm{~h}$ ) of the GNS-PEG-CD44 (the first panel - sub tumor, the second panel - orthotopic tumor), GNS-PEG-CD44v6 (the third panel - sub tumor, the fourth panel - orthotopic tumor) and GNS-PEG (the fifth panel - control). 


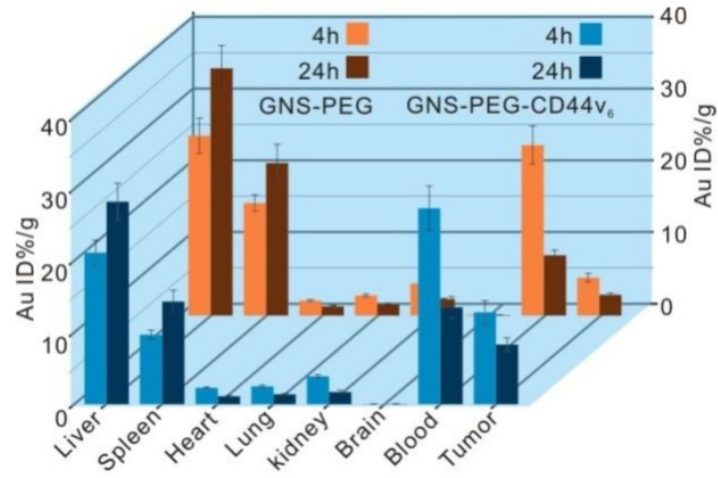

Fig. 8. Biodistribution of nanoprobes in organs of tumor-bearing mice after $4 \mathrm{~h}$ and $24 \mathrm{~h}$ intravenous injection with $150 \mu \mathrm{L}$ GNS-PEG-CD44v6 and GNS-PEG respectively $(0.867 \mathrm{mg} \mathrm{Au} / \mathrm{mL})$. Error bars were based on triplet measurements.

\subsection{ICP-MS analysis}

The biodistribution and uptake of GNS-PEG-CD44v6 and GNS-PEG in the main organs of GC bearing mice were quantified by ICP-MS. It is generally appreciated that the biodistribution of gold nanoparticles highly depends on the surface ligands, sizes, and shapes. We analyzed the gold concentrations at $4 \mathrm{~h}$ and $24 \mathrm{~h}$ after a one-dose injection $(150 \mu \mathrm{L}$, $0.867 \mathrm{mg} \mathrm{Au} / \mathrm{mL}$ ). The nanoparticles were mainly accumulated in the tumor and reticuloendothelial system (RES) such as the liver and spleen (Fig. 8), while the Au contents were barely detectable in the heart, lung, kidney, and brain, which was similar to previous reports [50]. Additionally, antibody conjugation reduced the non-specific accumulation in the liver and spleen at $24 \mathrm{~h}$ (GNS-PEG-CD44v6 liver: $28.2 \%$, spleen: $14.3 \%$; and GNS-PEG liver: $34.5 \%$, spleen: $21.3 \%$ ). The ratios of the probes accumulated in the brain, kidney, heart, and lung were all below $5 \%$. The Au content in tumors reached a maximum at $4 \mathrm{~h}$ in both groups, while a gradual step-down trend was detected subsequently. However, the Au content accumulated in the tumors in the mice injected with GNS-PEG-CD44v6 was found to be more than 2-fold higher than those injected with GNS-PEG. The superior accumulation behavior in the tumors could be contributed to the increased capacity to actively penetrate into the tumors, followed by preferential binding to receptors overexpressed in cancer cells. Active targeting schemes can enhance tumor delivery, retention, and specificity compared with their passive counterparts [58]. To summarize, the ICP-MS results implied that GNS-PEG-CD44v6 may serve as an efficiently targeted theranostic probe. Additionally, no significant weight loss or death of the GC xenografted mice was observed over four weeks after injection, indicating excellent biocompatibility of the synthesized probe in vivo.

\section{Conclusions}

In this study, we prepared branched GNSs-based PEGylated and CD44v6 monoclonal antibodies-conjugated nanoprobes, which showed excellent stability, high biocompatibility, targeting ability against CD44-expressing GCSCs, high photothermal conversion efficiency and photothermal ablation ability. Especially due to the remarkable heating features, the GNSs served as an attractive candidate for plasmonic photothermal agents, overcoming the resistance of CSCs to photodynamic therapy and general PTT. Moreover, our study provided new ideas and methods for the treatment of GC. The union of the PTT by the GNSs-based nanoprobes and traditional treatments may be an ideal strategy to improve the prognosis of GC and reduce recurrence, metastasis, and resistance to chemotherapy. In conclusion, the high performance of GNS-PEG-CD44v6 nanoprobes exhibit great potential for applications of GCSCs targeted imaging and PTT, as well as radical cures for GC in the near future.

\section{Acknowledgements}

This work was supported by Chinese Key Basic Research Program (973 Project) (No. 2010CB933901and 2015CB931802), the National Natural Scientific Foundation of China (Grant No. 81225010,81327002 , and 31170961), and 863 project of China (No.2012AA022703 and 2014AA020700), Shanghai Science and Technology Fund (No.13NM1401500). We also give thanks to the support for PA imaging from molecular imaging and Translational medicine of Xiamen University.

\section{Supplementary Materials}

Figures S1-S7. http://www.thno.org/v05p0970s1.pdf

\section{Competing Interests}

The authors have declared that no competing interest exists.

\section{References}

1. Cancer IAfRo. Globocan 2012: Estimated cancer incidence, mortality and prevalence worldwide in 2012. World Health Organization http://globocan iarc fr/Pages/fact sheets cancer aspx Accessed on. 2014; 9.

2. Siegel R, Naishadham D, Jemal A. Cancer statistics, 2013. CA Cancer J Clin. 2013; 63: 11-30.

3. Chen WQ, Zheng RS, Zhang SW, Zeng HM, Zou XN. The incidences and mortalities of major cancers in china, 2010. Chin J Cancer. 2014; 33: 402-5.

4. Takahashi T, Saikawa Y, Kitagawa Y. Gastric cancer: Current status of diagnosis and treatment. Cancers (Basel). 2013; 5: 48-63.

5. Vinogradov S, Wei X. Cancer stem cells and drug resistance: The potential of nanomedicine. Nanomedicine (Lond). 2012; 7: 597-615.

6. Zhang D, Fan D. New insights into the mechanisms of gastric cancer multidrug resistance and future perspectives. Future Oncol. 2010; 6: 527-37.

7. Stojnev S, Krstic M, Ristic-Petrovic A, Stefanovic V, Hattori T. Gastric cancer stem cells: Therapeutic targets. Gastric Cancer. 2013.

8. Clarke MF, Dick JE, Dirks PB, Eaves CJ, Jamieson CH, Jones DL, et al. Cancer stem cells-perspectives on current status and future directions: Aacr workshop on cancer stem cells. Cancer Res. 2006; 66: 9339-44. 
9. Gilbertson RJ, Graham TA. Cancer: Resolving the stem-cell debate. Nature. 2012; 488: 462-3

10. Lapidot T, Sirard C, Vormoor J, Murdoch B, Hoang T, Caceres-Cortes J, et al. A cell initiating human acute myeloid leukaemia after transplantation into scid mice. Nature. 1994; 367: 645-8.

11. Takaishi S, Okumura T, Tu S, Wang SS, Shibata W, Vigneshwaran R, et al. Identification of gastric cancer stem cells using the cell surface marker cd44. Stem Cells. 2009; 27: 1006-20.

12. Clement V, Marino D, Cudalbu C, Hamou MF, MLynarik V, de Tribolet N, et al. Marker-independent identification of glioma-initiating cells. Nat Methods. 2010; $7: 224-8$

13. Liu J, Ma L, Xu J, Liu C, Zhang J, Liu J, et al. Spheroid body-forming cells in the human gastric cancer cell line mkn- 45 possess cancer stem cell properties. International Journal of Oncology. 2013; 42: 453-9.

14. Li R, Wu X, Wei H, Tian S. Characterization of side population cells isolated from the gastric cancer cell line sgc-7901. Oncol Lett. 2013; 5: 877-83.

15. Xue Z, Yan $\mathrm{H}, \mathrm{Li}$ J, Liang $\mathrm{S}$, Cai X, Chen $\mathrm{X}$, et al. Identification of cancer stem cells in vincristine preconditioned sgc7901 gastric cancer cell line. Journal of Cellular Biochemistry. 2012; 113: 302-12.

16. Brabletz T, Jung A, Spaderna S, Hlubek F, Kirchner T. Opinion: Migrating cancer stem cells - an integrated concept of malignant tumour progression. Nat Rev Cancer. 2005; 5: 744-9.

17. Duan JJ, Qiu W, Xu SL, Wang B, Ye XZ, Ping YF, et al. Strategies for isolating and enriching cancer stem cells: Well begun is half done. Stem Cells and Development. 2013; 22: 2221-39.

18. Marhaba R, Klingbeil P, Nuebel T, Nazarenko I, Buechler MW, Zoeller M. Cd44 and epcam: Cancer-initiating cell markers. Curr Mol Med. 2008; 8: 784-804

19. Prud'Homme GJ. Cancer stem cells and novel targets for antitumor strategies. Curr Pharm Des. 2012; 18: 2838-49.

20. Chen T, Yang K, Yu J, Meng W, Yuan D, Bi F, et al. Identification and expansion of cancer stem cells in tumor tissues and peripheral blood derived from gastric adenocarcinoma patients. Cell Res. 2012; 22: 248-58.

21. Zhang C, Li C, He F, Cai Y, Yang H. Identification of cd $44+\mathrm{cd} 24+$ gastric cancer stem cells. J Cancer Res Clin Oncol. 2011; 137: 1679-86.

22. Chen W, Zhang X, Chu C, Cheung WL, Ng L, Lam S, et al. Identification of cd44+ cancer stem cells in human gastric cancer. Hepatogastroenterology. 2013; 60: 949-54

23. Misra S, Heldin P, Hascall VC, Karamanos NK, Skandalis SS, Markwald RR, et al. Hyaluronan-cd44 interactions as potential targets for cancer therapy. FEBS J. 2011; 278: 1429-43.

24. Yoshida M, Yasuda T, Hiramitsu T, Ito H, Nakamura T. Induction of apoptosis by anti-cd44 antibody in human chondrosarcoma cell line sw1353. Biomed Res. 2008; 29: 47-52.

25. Jang BI, Li Y, Graham DY, Cen P. The role of cd44 in the pathogenesis, diagnosis, and therapy of gastric cancer. Gut Liver. 2011; 5: 397-405.

26. Heider KH, Kuthan H, Stehle G, Munzert G. Cd44v6: A target for antibody-based cancer therapy. Cancer Immunol Immunother. 2004: 53: 567-79.

27. Chen Y, Huang K, Li X, Lin X, Zhu Z, Wu Y. Generation of a stable anti-human cd44v6 scfv and analysis of its cancer-targeting ability in vitro. Cancer Immunol Immunother. 2010; 59: 933-42.

28. Naor D, Sionov RV, Ish-Shalom D. Cd44: Structure, function, and association with the malignant process. Adv Cancer Res. 1997; 71: 241-319.

29. Wang X, Yang L, Chen ZG, Shin DM. Application of nanotechnology in cancer therapy and imaging. CA Cancer J Clin. 2008; 58: 97-110.

30. Dong K, Liu Z, Li Z, Ren J, Qu X. Hydrophobic anticancer drug delivery by a $980 \mathrm{~nm}$ laser-driven photothermal vehicle for efficient synergistic therapy of cancer cells in vivo. Adv Mater. 2013; 25: 4452-8.

31. Yang X, Liu X, Liu Z, Pu F, Ren J, Qu X. Near-infrared light-triggered, targeted drug delivery to cancer cells by aptamer gated nanovehicles. Adv Mater. 2012; 24: $2890-5$.

32. Kim C, Song HM, Cai X, Yao J, Wei A, Wang LV. In vivo photoacoustic mapping of lymphatic systems with plasmon-resonant nanostars. J Mater Chem. 2011; 21: 2841-4.

33. Wang S, Huang P, Nie L, Xing R, Liu D, Wang Z, et al. Single continuous wave laser induced photodynamic/plasmonic photothermal therapy using photosensitizer-functionalized gold nanostars. Adv Mater. 2013; 25: 3055-61.

34. Chen R, Wang X, Yao X, Zheng X, Wang J, Jiang X. Near-ir-triggered photothermal/photodynamic dual-modality therapy system via chitosan hybrid nanospheres. Biomaterials. 2013; 34: 8314-22.

35. Yuan H, Khoury CG, Hwang H, Wilson CM, Grant GA, Vo-Dinh T. Gold nanostars: Surfactant-free synthesis, 3d modelling, and two-photon photoluminescence imaging. Nanotechnology. 2012; 23: 075102.

36. Park J, Ku M, Kim E, Park Y, Hong Y, Haam S, et al. Cd44-specific supramolecular hydrogels for fluorescence molecular imaging of stem-like gastric cancer cells. Integr Biol (Camb). 2013; 5: 669-72.

37. Zieker D, Buhler S, Ustundag Z, Konigsrainer I, Manncke S, Bajaeifer K, et al. Induction of tumor stem cell differentiation-novel strategy to overcome therapy resistance in gastric cancer. Langenbecks Arch Surg. 2013; 398: 603-8.

38. Choi J, Yang J, Bang D, Park J, Suh JS, Huh YM, et al. Targetable gold nanorods for epithelial cancer therapy guided by near-ir absorption imaging. Small. 2012; 8: 746-53.

39. Yuan H, Khoury CG, Wilson CM, Grant GA, Bennett AJ, Vo-Dinh T. In vivo particle tracking and photothermal ablation using plasmon-resonant gold nanostars. Nanomedicine. 2012; 8: 1355-63.
40. Van de Broek B, Devoogdt N, D'Hollander A, Gijs HL, Jans K, Lagae L, et al. Specific cell targeting with nanobody conjugated branched gold nanoparticles for photothermal therapy. ACS Nano. 2011; 5: 4319-28.

41. Park J, Ku M, Kim E, Park Y, Hong Y, Haam S, et al. Cd44-specific supramolecular hydrogels for fluorescence molecular imaging of stem-like gastric cancer cells. Integrative Biology. 2013; 5: 669-72.

42. Jin L, Hope KJ, Zhai O, Smadja-Joffe F, Dick JE. Targeting of cd44 eradicates human acute myeloid leukemic stem cells. Nat Med. 2006; 12: 1167-74.

43. Burke AR, Singh RN, Carroll DL, Wood JC, D'Agostino Jr. RB, Ajayan PM, et al. The resistance of breast cancer stem cells to conventional hyperthermia and their sensitivity to nanoparticle-mediated photothermal therapy. Biomaterials. 2012; 33: 2961-70.

44. Lee E, Hong Y, Choi J, Haam S, Suh JS, Huh YM, et al. Highly selective cd44-specific gold nanorods for photothermal ablation of tumorigenic subpopulations generated in mcf7 mammospheres. Nanotechnology. 2012; 23: 465101.

45. Wang $\mathrm{CH}$, Chiou $\mathrm{SH}$, Chou $\mathrm{CP}$, Chen $\mathrm{YC}$, Huang YJ, Peng CA. Photothermolysis of glioblastoma stem-like cells targeted by carbon nanotubes conjugated with cd133 monoclonal antibody. Nanomedicine. 2011; 7: 69-79.

46. Weissleder R. A clearer vision for in vivo imaging. Nat Biotechnol. 2001; 19: 316-7.

47. Pan B, Cui D, Xu P, Ozkan C, Feng G, Ozkan M, et al. Synthesis and characterization of polyamidoamine dendrimer-coated multi-walled carbon nanotubes and their application in gene delivery systems. Nanotechnology. 2009; 20: 125101.

48. Huang P, Xu C, Lin J, Wang C, Wang X, Zhang C, et al. Folic acid-conjugated graphene oxide loaded with photosensitizers for targeting photodynamic therapy. Theranostics. 2011: 1: 240-50.

49. Li Z, Huang P, Zhang X, Lin J, Yang S, Liu B, et al. Rgd-conjugated dendrimer-modified gold nanorods for in vivo tumor targeting and photothermal therapy. Mol Pharm. 2010; 7: 94-104.

50. Nie L, Wang S, Wang X, Rong P, Ma Y, Liu G, et al. In vivo volumetric photoacoustic molecular angiography and therapeutic monitoring with targeted plasmonic nanostars. Small. 2014; 10: 1585-93.

51. Nie L, Chen X. Structural and functional photoacoustic molecular tomography aided by emerging contrast agents. Chem Soc Rev. 2014; 43: 7132-70.

52. Li W, Sun $X$, Wang $Y$, Niu G, Chen $X$, Qian Z, et al. In vivo quantitative photoacoustic microscopy of gold nanostar kinetics in mouse organs. Biomedical optics express. 2014; 5: 2679-85.

53. Nie L, Huang P, Li W, Yan X, Jin A, Wang Z, et al. Early-stage imaging of nanocarrier-enhanced chemotherapy response in living subjects by scalable photoacoustic microscopy. ACS Nano. 2014; 8: 12141-50.

54. Dondapati SK, Sau TK, Hrelescu C, Klar TA, Stefani FD, Feldmann J. Label-free biosensing based on single gold nanostars as plasmonic transducers. ACS Nano. 2010; 4: 6318-22.

55. Gutrath BS, Beckmann MF, Buchkremer A, Eckert T, Timper J, Leifert A, et al. Size-dependent multispectral photoacoustic response of solid and hollow gold nanoparticles. Nanotechnology. 2012; 23: 225707.

56. Chen YS, Frey W, Aglyamov S, Emelianov S. Environment-dependent generation of photoacoustic waves from plasmonic nanoparticles. Small. 2012; 8: 47-52.

57. Cheng Y, Meyers JD, Broome AM, Kenney ME, Basilion JP, Burda C. Deep penetration of a pdt drug into tumors by noncovalent drug-gold nanoparticle conjugates. Journal of The American Chemical Society. 2011; 133: 2583-91.

58. Sykes EA, Chen J, Zheng G, Chan WC. Investigating the impact of nanoparticle size on active and passive tumor targeting efficiency. ACS Nano. 2014; 8: 5696-706. 